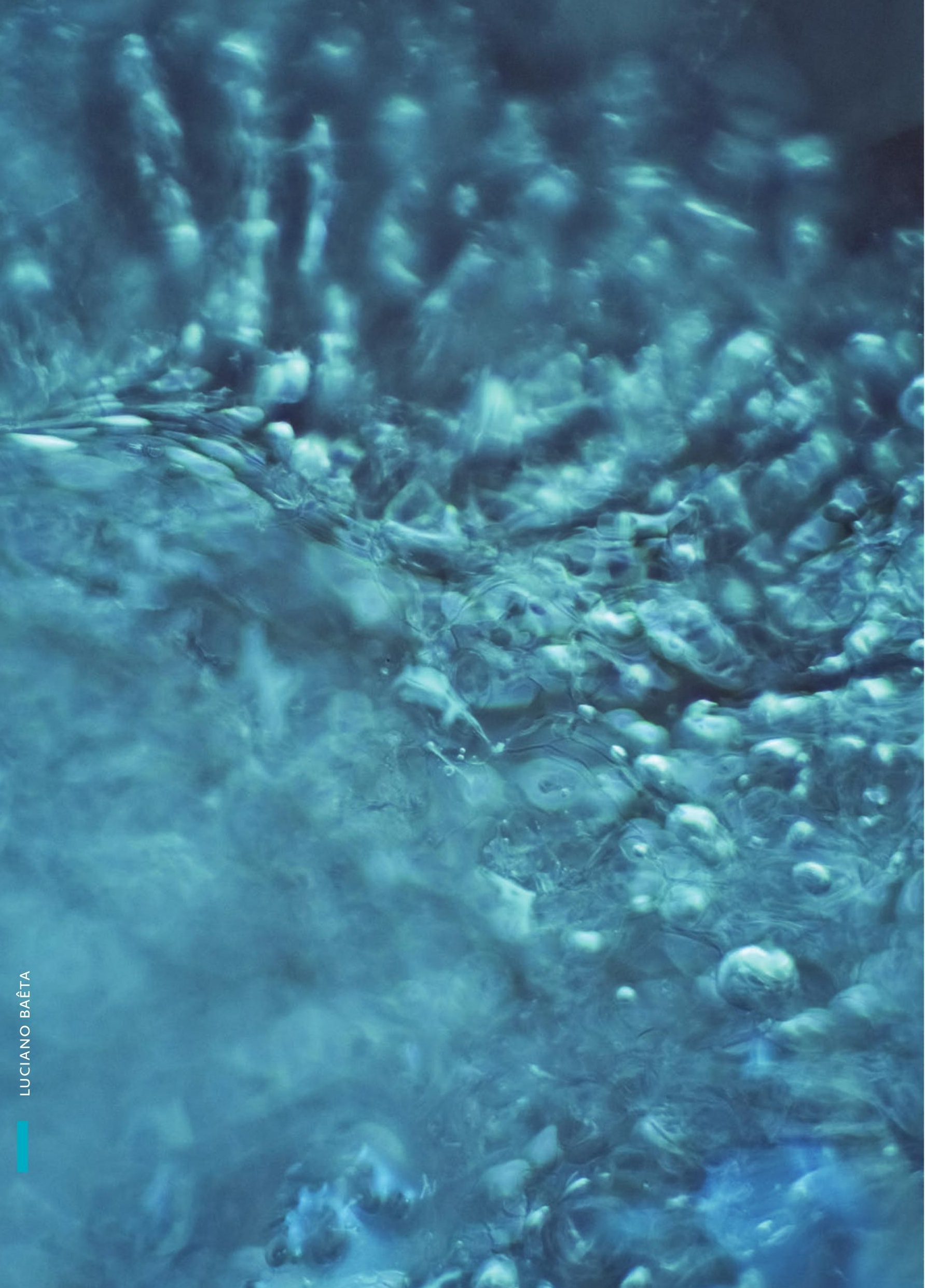




\section{GOVERNANÇA DA ÁGUA}

\section{JOSÉ GALIZIA TUNDISI*}

RESUMO Este trabalho trata da governança da água relativamente aos processos de integração da gestão e montagem de um sistema operacional que envolva bases científicas e tecnológicas, sistemas de suporte para a decisão e participação da comunidade. O trabalho examina a evolução do conceito de gestão integrada de recursos hídricos e apresenta soluções para a implementação de uma governança de bacia hidrográfica, com integração de dados de águas atmosféricas superficiais e subterrâneas e com caráter preditivo, de tal forma a antecipar eventos, minimizar impactos e promover ações para melhorar a qualidade da água e administrar as relações, suprimento-demanda de água.

PALAVRAS-CHAVE Governança da água. Bacias hidrográficas. Integração.

\section{WATER GOVERNANCE}

ABSTRACT Water governance in connection with management integration and planning of an operational system involving scientific and technological bases, besides supporting systems for community participation and decision are approached. Not only the evolution of the concept of water resources integrated management is examined, but also are presented solutions for the implementation of a watershed governance with the incorporation of preventive data on atmospheric, superficial and underground waters in order to foresee events, minimize impacts, and promote actions to improve water quality and manage the water supply-demand relationship.

KEYWORDS Water governance. Watersheds. Integration.

*Pesquisador e presidente do Instituto Internacional de Ecologia de São Carlos. Professor Titular da Universidade Feevale (Novo Hamburgo, RS). 
água é um recurso natural de extrema importância para o planeta Terra.
É essencial à vida humana e à manutenção da biodiversidade terrestre e aquática, impulsiona os ciclos biogeoquímicos e o funcionamento dos ecossistemas. A água tem, também, um papel econômico de grande relevância, uma vez que seus usos múltiplos - abastecimento público, produção de alimentos, geração de hidroeletricidade, navegação e desenvolvimento industrial - promovem as economias locais, regionais e nacionais (BRAGA et al., 2008). A gestão dos recursos hídricos, a governança da água, é, portanto, um fator essencial no desenvolvimento territorial e econômico, tornandose um componente estratégico de grande relevância, especialmente neste século XXI, em que os usos múltiplos e competitivos se acentuam e colocam pressões adicionais sobre quantidade e qualidade da água. À medida que a economia se desenvolve e se diversifica, maior é a necessidade de uma gestão eficiente e participativa, de forma a contribuir para gerenciar a escassez ou o estresse hídrico, regular a demanda e compartilhar os usos múltiplos.

\section{A evolução do processo de gestão ou governança da água}

A gestão das águas na maior parte do século XX foi centralizada e setorial. A preocupação fundamental era com o abastecimento público, a qualidade da água para o suprimento à população humana e a pesca e navegação. Cada uso da água tinha uma administração que era geralmente dirigida por um Ministério ou Secretaria nacional. Assim, em muitos países, havia um Ministério de Irrigação - essencial no controle da água para a produção de alimentos.

A gestão das águas era também voltada para solução de problemas resultantes de contaminação ou desastres - enchentes, mortalidade de peixes, episódios de poluição e 
despejos industriais. Outro aspecto importante nessa gestão é que o enfoque e o objeto principal era no corpo de água-rio, lago, ou represa, uma vez que era esta a fonte principal de abastecimento ou uso. Nas duas últimas décadas do século XX, novas iniciativas na legislação e na organização institucional começaram a ser implementadas, tornando a gestão das águas mais eficiente, mais abrangente e sistêmica, promovendo ações que visavam modernizar o processo. Desde a conferência de Dublin em I992, significativos avanços foram consta- A gestão dos recursos hídricos, a tados no cenário internacional.

No Fórum Mundial da Água em 2000, o "Global Water Partnership Framework for Action", declarou-se que a crise da água governança da águra, é, portanto, um fator essencial no desenvolvimento territorial e econômico, tornandose um componente estratégico de é essencialmente uma crise de gestão e, consequente- grande relevância. mente, a governança da água é uma das grandes prioridades para a ação. A evolução do processo de governança passou, portanto, para uma gestão de bacia hidrográfica, integrando-se ações para usos múltiplos, ou seja, servindo os usos múltiplos de forma integrada e não setorial; e tornando-se essencialmente preditiva, com a finalidade de antecipar processos e fenômenos. Esta evolução na governança da água tem um papel relevante também na descentralização do processo, ou seja, aplicando-se a gestão de bacia hidrográfica na menor escala possível. Outra evolução na gestão, partindo dos Princípios da Água de Dublin (I992), é o reconhecimento do valor econômico da água e sua importância no desenvolvimento local e regional.

Os Princípios da Água de Dublin (I992) consideram:

- a água como um recurso finito e vulnerável essencial para sustentar a vida, o desenvolvimento e o funcionamento dos ecossistemas;

- o desenvolvimento da gestão das águas deve ser baseado em uma abordagem participativa, envolvendo planejadores x gerentes e tomadores de decisão em todos os níveis;

- as mulheres têm um papel central na provisão, gerenciamento e conservação da água; - a água tem um valor econômico, em todos os seus usos competitivos, e deve ser reconhecida como um recurso natural pelos serviços prestados: abastecimento, hidroeletricidade, produção de alimentos. 
Sobre esta base conceitual ocorreram, portanto, avanços institucionais significativos e propostas com novas abordagens e visões na governança da água.

\section{A governança das águas no Brasil \\ Organização e desafios}

O Sistema Nacional de Gerenciamento de Recursos Hídricos (SINGREH) é resultado da regulamentação da Lei das Águas, a Lei nº 9.433, de I997. Esta lei das águas traz novas iniciativas na descentralização e na utilização de instrumentos econômicos para a gestão e enfatiza a participação pública no processo de gestão. A Lei das Águas se refere a uma gestão descentralizada, priorizando o processo de bacias hidrográficas e remetendo o abastecimento público e o saneamento básico à responsabilidade dos municípios. É necessário, portanto, um sistema de integração da gestão entre União, estados e municípios, constituindo-se esta articulação uma das mais importantes etapas na gestão. Para melhor compreender a relevância da gestão das águas no Brasil, devem-se destacar dois aspectos fundamentais enfatizados por Braga et al. (2008) e Disponibilidade e demanda são Tundisi e Matsumura Tundisi (20II): importantes componentes da gestão, pois estabelecem limites para a outorga

o primeiro é a nova organização das bacias hidrográe propõem ordenamento de usos. lidade de análise conceitual dos recursos hídricos (FIG. I). Essa organização e os limites das bacias não coincidem com os limites geopolíticos dos estados brasileiros, sendo uma tipologia derivada de bases geofisiográficas. A vazão média para todo o território brasileiro é de $179.433 \mathrm{~m}$ /s, o que implica que o país detém I2\% das reservas mundiais de água; entretanto, ela não é uniformemente distribuída com relação à população e às atividades industriais e agrícolas, o que resulta em desafios regionais para a gestão dos recursos hídricos. Há uma variação estacional da disponibilidade de águas que também deve ser considerada como importante no planejamento e ações para a gestão. Quanto aos usos múltiplos da água no Brasil, outro problema fundamental para a gestão é que 70\% dos recursos hídricos são utilizados para irrigação; ıı\% são derivados no abastecimento 
urbano; dessedentação animal ıo\%; uso industrial 7\%; e abastecimento rural 2\%. São, em algumas regiões do Brasil, usos competitivos que demandam gestão de alto nível, integrada e com participação de usuários. Disponibilidade e demanda são importantes componentes da gestão, pois estabelecem limites para a outorga e propõem ordenamento de usos. Há algumas regiões, como o Nordeste ou o Sudeste e o Sul do Brasil, em que a demanda é elevada e o comprometimento das águas pela poluição dificulta os usos múltiplos e encarece o tratamento da água.

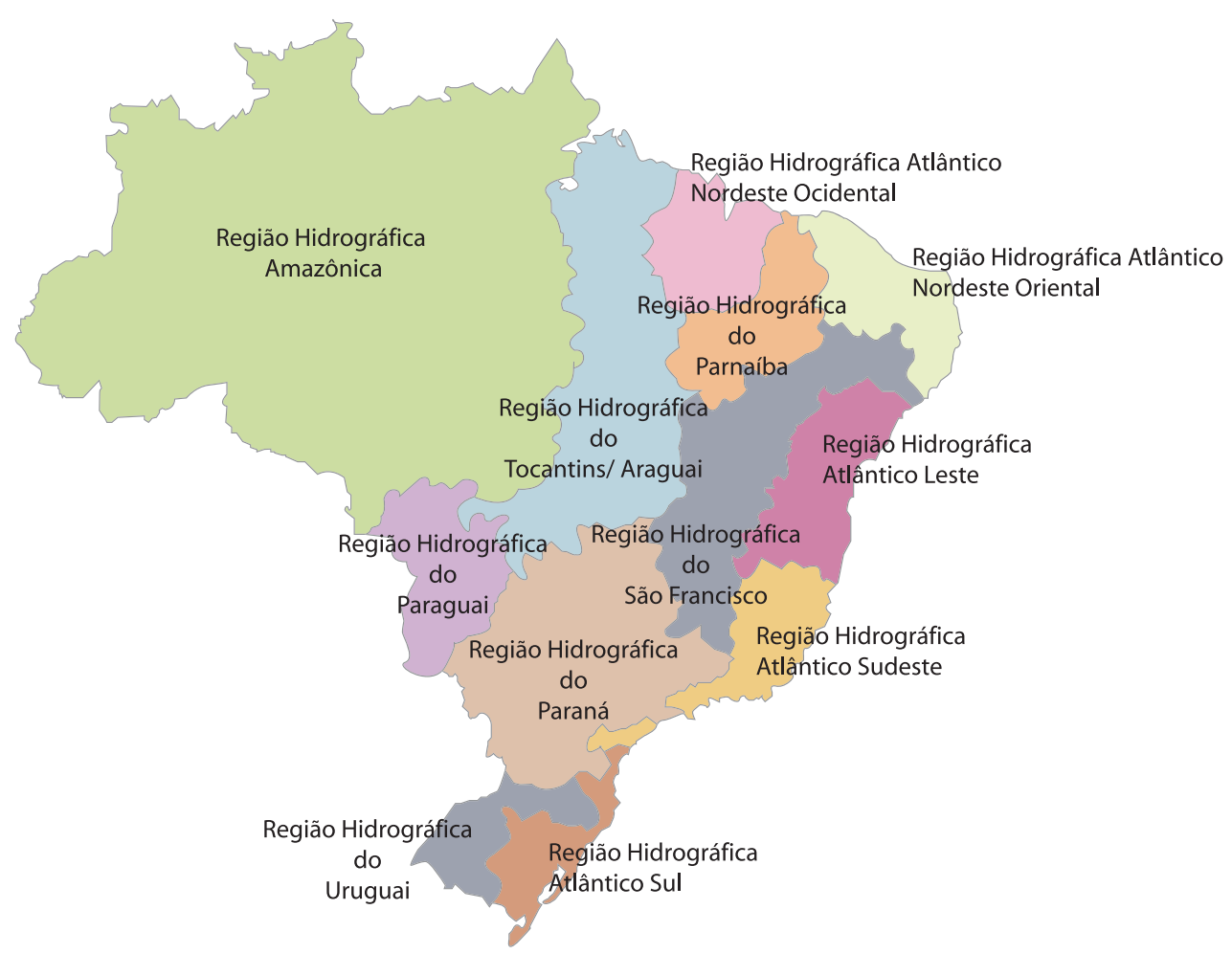

FIGURA 1 - Regiões hidrográficas brasileiras

Fonte: CNRH (2003).

\section{Os problemas na gestão}

A demanda, portanto, deve ter um forte componente da gestão, pois ela deve ser regulada pela disponibilidade de recursos hídricos e, além disso, outra importante etapa da gestão é o controle da poluição industrial e doméstica. Mesmo com alguns 
avanços no tratamento de esgotos domésticos, somente $30 \%$ destes são tratados no Brasil. O controle de poluição industrial tem sido mais efetivo que o controle de poluição doméstica que é resultado da gestão ineficiente em âmbito municipal. Há ainda uma poluição difusa resultante de usos do solo, aplicação de fertilizantes e pesticidas na zona rural que tem tido pouco controle.

A gestão da demanda e da disponibilidade e o controle da poluição hídrica necessitam de aportes e avanços tecnológicos que deverão ser implantados nas bacias hidrográficas para uma gestão integrada e eficiente dos recursos hídricos.

\section{O Sistema Nacional de Gerenciamento de Recursos Hídricos}

A disponibilidade da água para as futuras gerações e para a geração atual é o objetivo principal da Política Nacional de Recursos Hídricos (Lei nº 9.433 - Lei das Águas). A gestão integrada dos recursos hídricos deve assegurar quantidade e qualidade adequada, desenvolvimento sustentável e utilização racional (BRAGA et al., 2008). Esta Política Nacional de Recursos Hídricos se baseia, portanto, nos seguintes princípios:

- água como bem público e com valor econômico;

- segurança para os usos múltiplos da água;

- abastecimento público e para dessedentação de animais como garantia em caso de escassez;

- adoção como unidade de gestão territorial e de recursos hídricos;

- garantia da participação da sociedade civil, dos usuários e dos diferentes níveis do poder público no processo de gestão participativa.

Os avanços nesta política estão voltados principalmente para a gestão dos usos Mesmo com alguns avanços no tratamento múltiplos, o abasde esgotos domésticos, somente 30\% tecimento da água destes são tratados no Brasil. como prioridade e a gestão da disponibilidade e demanda, utilizando-se a divisão natural do território - a bacia hidrográfica - como unidade. A gestão participativa é outro avanço significativo no processo.

O Sistema Nacional de Gerenciamento de Recursos Hídricos (SINGREH) é composto por: Conselho Nacional de Recursos Hídricos; Secretaria de Recursos Hídricos; 
Agência Nacional de Águas; Conselho Estadual de Recursos Hídricos; Gestor Estadual de Recursos Hídricos; Comitês de Bacias Hidrográficas; Agências de Bacia.

\section{A bacia hidrográfica como unidade de gestão}

\section{Principais avanços}

A bacia hidrográfica - uma unidade biogeofisiográfica -, considerada como uma nova abordagem no processo de gestão de recursos hídricos, constitui um dos principais avanços conceituais na governança desses recursos. A abordagem por bacias hidrográficas tem as seguintes vantagens e situações, que são fundamentais para a gestão:

- a bacia hidrográfica é uma unidade física com fronteiras delimitadas, podendo estender-se por várias escalas espaciais, desde pequenas bacias de 100 a $200 \mathrm{~km}^{2}$ até grandes bacias hidrográficas, como a Bacia do Prata (3 milhões de $\mathrm{km}^{2}$ );

- é um ecossistema hidrologicamente integrado, com componentes e subsistemas interativos;

- oferece oportunidade para o desenvolvimento de parcerias e a resolução de conflitos;

- permite que a população local participe do processo de decisão;

- estimula a participação da população e a educação ambiental e sanitária;

- garante visão sistêmica adequada para o treinamento em gerenciamento de recursos hídricos e para o controle de eutrofização (gerentes, tomadores de decisão e técnicos); - é uma forma racional de organização do banco de dados;

- garante alternativas para o uso dos mananciais e de seus recursos;

- é uma abordagem adequada para proporcionar a elaboração de um banco de dados sobre componentes biogeofísicos, econômicos e sociais;

- sendo uma unidade física, com limites bem definidos, o manancial garante uma base de integração institucional;

- a abordagem de manancial promove a integração de cientistas, gerentes e tomadores de decisão com o público em geral, permitindo que eles trabalhem juntos em uma unidade física com limites definidos;

- promove a integração institucional necessária para o gerenciamento do desenvolvimento sustentável. 
Portanto, o conceito de bacia hidrográfica aplicado ao gerenciamento de recursos hídricos estende as barreiras políticas tradicionais (municípios, estados e países) para uma unidade física de gerenciamento, planejamento econômico e social.

\section{Principais desafios}

A unidade bacia hidrográfica, como sistema de planejamento territorial e de recursos hídricos, pressupõe um conjunto de planos, ações e atividades que re-

A bacia hidrográfica como unidade de gestão deve considerar três níveis para a gestao integrada de gerenciamento de recursos hídricos: o nivel organizacional, o nivel constitucional e o nivel operacional. presentam uma etapa significativa no planejamento territorial e na gestão integrada de recursos hídricos. Como discutido por Porto e La Laina Porto (2008), a bacia hidrográfica é uma unidade sistêmica cuja conexão se dá pelo rio principal como escoadouro e suas sub-bacias e agrega todas as atividades humanas em seus territórios. Áreas industriais, áreas preservadas são parte deste conjunto que compreende usos do solo; demanda e disponibilidade de água; contaminação e poluição; mananciais de abastecimento de água superficial e subterrânea.

Os principais desafios nesta gestão integrada de recursos hídricos das bacias hidrográficas são:

- integrar os três componentes de distribuição e disponibilidade de águas: atmosférico, superficial e subterrâneo;

- identificar e quantificar a demanda e estabelecer critérios para usos múltiplos e outorgas;

- determinar e quantificar a disponibilidade;

- determinar os principais indicadores da bacia: indicadores de qualidade da água dos rios, riachos, represas, lagos e lagoas; biodiversidade terrestre e aquática; taxa de contaminação de rios, lagos e represas; cargas de poluentes; cargas pontuais e difusas; usos do solo; áreas de preservação;

- promover o sistema de informações sobre recursos hídricos;

- enquadramento dos corpos de águas em classes de usos predominantes; 
- cobrança pelo uso dos recursos hídricos;

- gestão municipal integrada (TUCCI, 20Io).

\section{A governança ideal}

A bacia hidrográfica como unidade de gestão deve considerar três níveis para a gestão integrada de gerenciamento de recursos hídricos: o nível organizacional, o nível constitucional e o nivel operacional:

- o nível organizacional coordena e reduz conflitos entre os usos competitivos e os diferentes interesses; este é o comitê de bacia hidrográfica e a agência de bacia; - o nível constitucional agrega as gestões referentes à legislação, ao enquadramento dos corpos de água, ao planejamento territorial vis-à-vis o uso dos recursos hídricos;

- e o nível operacional tem foco na variedade de sistemas existentes: proteção de mananciais; hidroeletricidade; tratamento de esgotos; suprimento e abastecimento de água para os municípios, irrigação, gerenciamento ambiental, atividades estas sob responsabilidade pública ou privada (ROGERS, 2006).

A governança ideal, portanto, repousa sob a égide de uma sociedade de bacia hidrográfica com interesses comuns e inclui planejamento, gestão e execução em um mesmo contexto sistêmico, funcional e operacional. Há ainda novas abordagens, como as diretrizes para a gestão das águas da União Europeia (2000), com os seguintes arcabouços:

- Sobre o gerenciamento de bacias hidrográficas: os estados-membros deverão identificar as bacias hidrográficas de seu território e colocá-las em distritos individuais de bacias hidrográficas. Todos os Estados-membros devem assegurar que as bacias hidrográficas terão um Plano de Gerenciamento das Bacias em seu território;

- Sobre as questões ambientais: os Estados-membros deverão proteger e restaurar seus ecossistemas aquáticos com o objetivo de proporcionar água de boa qualidade até I5 anos após a emissão destas diretrizes. A proteção de águas subterrâneas, bem como a sua restauração, fica incluída nestas diretrizes. Deve ser assegurado equilíbrio adequado entre a retirada das águas subterrâneas e a recarga do aquífero;

- Sobre os custos da água: fica assegurado que, em 20ıo, o princípio da recuperação dos 
custos dos serviços de água, incluindo custos ambientais, deve estar implementado em todos os Estados-membros, utilizando o princípio do poluidor pagador, a fim de promover incentivos adequados para os usuários que utilizam os recursos eficientemente;

- Sobre informação e consulta: os Estados-membros devem encorajar a participação ativa de todas as partes interessadas na implementação destas diretrizes, em particular na produção, revisão e atualização dos Planos de Gerenciamento de Bacias “(...) para cada bacia hidrográfica, deverão ser publicados os planos e estar disponíveis para comentários (...)”. O cronograma de ações deve ser disponibilizado e revisões periódicas com adaptações do plano devem ser asseguradas;

- Sobre política integrada: a integração da proteção e do gerenciamento sustentável de água deve considerar as interseções entre as várias políticas de gerenciamento das águas para a comunidade, como energia, transporte, agricultura, pesca, política regional e turismo;

- Sobre substâncias perigosas: o Parlamento Europeu e o Conselho dos Estados-membros devem assegurar a adoção de medidas específicas para conter poluentes em grupos de poluentes que apresentam risco para substâncias tóxicas, com a redução progressiva e a cessação definitiva de descargas, emissões ou perdas (por desastre).

Além destas propostas e ações, deve-se considerar que, na governança ideal, o banco de dados e o sistema de informações, a disseminação da informação, a interação entre os setores acadêmicos, público e privado, nos comitês de bacia, são o futuro do processo de gestão (TUNDISI; MATSUMURA TUNDISI, 20Io). A implementação deste conjunto já tem sido desenvolvida em experiências e projetos em andamento no A governança ideal, portanto, repousa sob a égide de uma sociedade de bacia hidrográfica com interesses comuns e inclui planejamento, gestão e execução em um mesmo contexto sistêmico, funcional e operacional. e nos comitês de sub-bacias, na gestão de recursos hídricos do estado de São Paulo. Deve-se destacar a articulação federativa entre ANA, CEIVAP e estados de Minas, São Paulo e Rio de Janeiro, para a gestão desta bacia interestadual (BRAGA et al., 2008). 


\section{Conclusões}

Os avanços conceituais na legislação e na organização institucional que promoveram uma nova perspectiva na governança da água, no final do século XX e no início do XXI, possibilitaram uma maior inserção da descentralização na gestão e na visão preditiva, ecossistêmica (no nível de bacias hidrográficas) e integrada (integrando-se os usos múltiplos e os ciclos atmosféricos, superficiais e subterrâneos). Com os conceitos fundamentados e em andamento e articulações estabelecidas, o componente estratégico tecnológico e científico na gestão das bacias tem preponderância devido à necessidade de apoiar decisões, propostas e ações em fatos concretos e bancos de dados com informações confiáveis: séries históricas, avaliações de qualidade e quantidade da água, relações disponibilidade/demanda e caracterização dos usos do solo, fontes de contaminação e poluição (difusas e pontuais), biodiversidade e áreas preservadas.

Uma outra ideia e conceito avançado mais recente (PERIOTTO; TUNDISI, 20I3) é o estudo e a avaliação dos serviços ecossistêmicos da bacia hidrográfica que adicionará outros componentes científicos, tecnológicos e econômicos ao processo de gestão e, sem dúvida, promoverá novas perspectivas na governança das águas no Brasil.

Os cinco princípios que devem ser consolidados em um Programa de Gerenciamento Integrado de Bacias Hidrográficas e de Recursos Hídricos são:

I. Instituições: desenvolvendo organizações objetivas que integrem pesquisa, desenvolvimento tecnológico e gerenciamento.

2. Participação: estendendo o ciclo do envolvimento da sociedade com a implantação de mecanismos regionais.

3. Tecnologia: possibilidades e limitações. Intervenções técnicas que podem consolidar o desenvolvimento e os sistemas de informação e proteção da bacia hidrográfica são fundamentais para um avanço na gestão. Banco de dados, sistemas de informação, monitoramento e fundamentação científica para os comitês de Bacia e os tomadores de decisão são relevantes instrumentos para a gestão integrada. 
1. Fonte: RCSE, Shiga, Japão e ILEC (International Lake Enviroment Committee, Japan).
4. Informação: aprofundando as fontes de conhecimento e a visão. É necessário um contínuo processo de avaliação, diagnóstico, prognóstico realizado através de estudo científico e pesquisa; disseminação dos resultados da pesquisa aceleram as respostas sociais.

5. Financiamento: a alocação de fundos deve considerar recursos para pesquisa, monitoramento, informação e gestão de forma a obter as melhores políticas públicas de longo prazo para o gerenciamento integrado das bacias hidrográficas e dos recursos hídricos. ${ }^{1}$

\section{Referências}

BRAGA, B. P. F. et al. Pacto federativo e gestão das águas. Dossiê Água - Estudos Avançados, São Paulo, v. 22, n. 63, p. I7-42, 2008.

BRASIL. Lei Federal $n^{\circ}$ 9.433, 8 de janeiro de 1997. Presidência da República - Casa Civil. Disponível em: <http://www.planalto.gov.br/ccivil_o3/LEIS/l9433.htm>. Acesso em: Io fev. 2014.

NAKAMURA, M.; RAST, W. Development of ILBM Plataform Process. RCSE, ILEC, 2011.76 p.

PERIOTTO, N. A.; TUNDISI, J. G. Ecosystem Services of UHE Carlos Botelho (LOBO/BROA): a New Approach for Management and Planning of Dams Multiple Uses. Brazilian Journal of Biology, v. 73 , n. 3, p. 47I-482, 2013 .

PORTO, M. F. A.; LA LAINA PORTO, R. Gestão de bacias hidrográficas. Estudos Avançados, São Paulo, v. 22, n. 63, p. 43-60, 2008.

ROGERS, P. P. Water Governance, Water Security and Sustainability. In: ROGERS, P. P.; LLANAS, R.; MARTINEZ-CORTINA, L. Water Crisis: Myth or Reality? London: Foundation Marcelino Botim; Taylor \& Francis, 2006. p. 3-35.

TUCCI, E. M. Urbanização e recursos hídricos. In: BICUDO, C. E. M.; TUNDISI, J. G.; SCHEUENTSUl, M. C. (Org.). Águas do Brasil: análises estratégicas. São Paulo: Academia Brasileira de Ciências; Instituto Botânica, 20I0. p. II3-I28.

TUNDiSi, J. G.; MATSUMURA TUNDISI, T. Água no século 21. São Paulo: Oficina de textos, 20 II.

TUNDISI; J. G.; MATSUMURA TUNDISI, T. Ciência, tecnologia, inovação e recursos hídricos: oportunidades para o futuro. In: BICUDO, C. E. M.; TUNDISI, J. G.; SCHEUENTSUL, M. C. (Org.). Águas do Brasil: análises estratégicas. São Paulo: Academia Brasileira de Ciências; Instituto Botânica, 2010. p. I79-I97. 
TUNDISI, J. G.

GOVERNANÇA DA ÁGUA

WATER FRAMEWORK DIRECTIVE - European Union. 2000.

WMO. The Dublin State Rent and Report of the Conference on Water and the Environmental:

Development Issues for the 21 ${ }^{\text {st }}$ Century, 26-3I, Dublin: Ireland, January I992. 